\title{
INDICADORES DE RESPONSABILIDADE SOCIAL: ESTUDO COMPARATIVO ENTRE EMPRESAS PÚBLICAS E PRIVADAS, BASEADO NO BALANÇO SOCIAL IBASE
}

\author{
Alexandre dos Reis' \\ Gino Giacomini Filho
}

\begin{abstract}
Resumo
O presente artigo procura discutir as diferenças e similaridades existentes entre as práticas e as ações de Responsabilidade Social desenvolvidas pelas empresas privadas e públicas. Este estudo comparativo de caráter exploratório foi realizado com base nas empresas detentoras do Selo Social IBASE, que publicaram seus Balanços Sociais no modelo proposto pelo instituto no ano de 2004. Para tal, além da pesquisa documental envolvendo os balanços publicados, uma revisão conceitual sobre os principais temas se fez necessária e também constitui parte do estudo. Os resultados encontrados fornecem dados mensuráveis e representativos sobre as principais características de ação social das empresas, propiciando uma análise comparativa e a emissão de considerações críticas, que por si só não findam, mas estabelecem uma possibilidade de diferentes leituras quanto aos modelos de gestão socialmente responsável empreendidos pelas empresas dos segmentos público e privado.
\end{abstract}

Palavras-chave: Responsabilidade Social. Balanço Social. Indicadores de Responsabilidade Social. Empresas Públicas.

\section{INTRODUÇÃO}

Foram muitas as mudanças ocorridas no cenário empresarial nas últimas décadas. As estruturas econômicas, políticas, sociais e culturais se alteraram profundamente em uma abrangência global.

Dentre as mudanças mais visíveis, podemos eleger a globalização de mercados, a velocidade da comunicação mundial, a dependência ao cenário externo e a adoção

\footnotetext{
Mestrando Programa de Mestrado em Administração da Universidade Municipal de São Caetano do Sul. Endereço: Rua Guararema 74I, Ap. 34, São Paulo, SP. CEP 04136-031.E-mail: alexandredosreis@petrobras.com.br.

2 Doutor e Livre-docente em Comunicação Social pela ECA/USP. Docente do Programa de Mestrado em Comunicação pela Universidade Municipal de São Caetano do Sul. Endereço: Rua Lucrécia Maciel, 236, ap. 9I, Vila Guarani, São Paulo-SP. CEP 043 I 4- 130. E-mail: gino.giacomini@uscs.edu.br. Artigo recebido em: 30/0 I/2006. Aceito em: 3 I / 1 0/2007. Membro do Corpo Editorial Cientíico responsável pelo processo editorial: Gilberto de Oliveira Moritz.
} 
de práticas liberalizantes fomentadas pelas nações desenvolvidas e adotadas pela maioria das nações em desenvolvimento, como as mais importantes.

A Responsabilidade Social Empresarial, termo em voga nos verbetes acadêmicos e empresariais atuais, se relaciona diretamente a este novo cenário.

A crise do Estado-Nação, ou seja, a sua diminuição enquanto agente garantidor do estado de bem-estar social, oriunda das ações neoliberalizantes dos governos, faz com que as empresas assumam uma nova posição, aumentando a sua importância como um dos agentes contribuintes para a organização da sociedade. As empresas emergem como um grande investidor social e como principal agente do desenvolvimento local e regional (KREITLON, 2004).

Nessa perspectiva, o novo papel assumido pelas empresas se efetiva num cenário de extrema competição ditada pelas regras de um mercado cada vez mais dinâmico. A operação das empresas de forma socialmente responsável deixa de ser um ato exclusivo de benevolência ou filantropia de grupos de dirigentes, para se tornar item fundamental na gestão estratégica das empresas.

Nesse novo contexto, as empresas transcendem o cenário econômico, acrescentando a perspectiva ética e moral nas suas relações com a sociedade.

As empresas públicas, ou seja, aquelas estatais ou de economia mista que possuem o Estado como controlador principal, também são afetadas por este novo cenário. Com a reforma geral do Estado Brasileiro, fenômeno que se opera no Brasil desde os anos de 1990 e que busca atribuir eficiência operacional na sua gestão, essas empresas também apresentam a necessidade latente de desenvolver ações objetivando uma gestão competitiva.

Trabalhos foram e vem sendo desenvolvidos na análise das ações de Responsabilidade Social Empresarial, mas o tema ainda representa um novo e complexo campo no ambiente acadêmico, implicando em um grande potencial para o desenvolvimento de pesquisas (BORGER, 2001).

Busca-se, neste trabalho, o desenvolvimento do conhecimento aliado a essas perspectivas, baseado, especificamente, na verificação das características das ações de Responsabilidade Social nas empresas públicas, oferecendo um contraponto comparativo às empresas privadas.

Para operacionalizar este estudo exploratório e comparativo será utilizado um meio de mensuração representado pela publicação do Balanço Social IBASE, que oferece uma base eqüitativa de comparação e dispõe de dados atuais e adequados nos diversos vieses da ação socialmente responsável.

O problema central deste estudo busca identificar as principais diferenças e similaridades entre as ações de Responsabilidade Social desenvolvidas pelas empresas públicas e as privadas e, como perspectiva secundária, identificar qual o perfil das ações de Responsabilidade Social desenvolvidas, especificamente, pelas empresas públicas. 
A análise da problematização proposta tem como objetivos principais (1) a verificação das diferenças e similaridades das ações de Responsabilidade Social desenvolvidas pelas empresas públicas e privadas e (2) a visualização das características dessas ações nas empresas públicas.

\section{O CONCEITO DE RESPONSABILIDADE SOCIAL}

A partir dos anos de 1960, o questionamento ético das empresas ganhou força na sociedade. Os EUA, ocupando uma posição hegemônica no capitalismo moderno, fomentam a discussão acerca da Responsabilidade Social, vindo a se institucionalizar na década de $1980 \mathrm{com}$ as correntes de pensamento conhecidas como Business Ethics, Social Issues Management e Business \& Society.

Num breve apanhado histórico, podem ser identificadas as principais fases do conceito de Responsabilidade Social:

- De 1900 a 1960 pode-se verificar a consolidação das práticas de Responsabilidade Social baseada em dois pilares básicos representados pela filantropia e governança, com ênfase na manifestação paternalista. A desilusão frente às promessas do liberalismo com o crash da Bolsa de Nova York em 1929, o desenvolvimento das Ciências Administrativas e a ascensão do socialismo são fatores que fomentam o desejo das empresas em melhorarem sua imagem frente à sociedade;

- De 1960 a 1980 pode-se verificar uma fase de mobilização cívica e progresso científico e tecnológico. As crises conjunturais do dólar e do petróleo ajudam a causar graves oscilações no sistema capitalista mundial. O ajustamento do capitalismo a este novo cenário, representando o germe do processo mais tarde conhecido como globalização, faz com que as empresas e os grandes conglomerados atinjam proporções inéditas, aumentado sua importância na organização social, e as transformando em alvos das reivindicações dos mais variados grupos. As discussões filosóficas acerca do papel da economia ressurgem, transformando as empresas em entidades morais;

- A partir dos anos de 1980 é possível verificar o ressurgimento das políticas neoliberais, com um tipo particular de capitalismo financeiro, que se desenvolve de forma desenfreada por todo o planeta. Com a diminuição do papel, e conseqüentes responsabilidades do Estado, as desigualdades e a exclusão social e a devastação ambiental se acentuam, na mesma medida em que a participação das empresas na organização social cresce. Nesse período de diversificação das correntes da Responsabilidade Social, a empresa se afirma como agente regulador de uma rede inextrincável de interesses e relações na sociedade. 
Em termos pontuais podemos entender Responsabilidade Social Empresarial como um compromisso das empresas em contribuir para o desenvolvimento econômico sustentável, trabalhando em conjunto com os empregados, suas famílias, a comunidade local e a sociedade em geral para melhorar a qualidade de vida, de uma maneira que seja boa tanto para as empresas como para o desenvolvimento (NETO; FROES, 2004). Pode também ser entendida como uma ação estratégica que busca retorno econômico, social, institucional e tributário-fiscal (KREITLON, 2004).

A preocupação com a ética e a responsabilidade social sai do foro interno na organização para se institucionalizar como uma obrigação moral; o genuíno sentido de cidadania ganha importância nesse contexto. As empresas não assumem a prerrogativa exclusiva de agentes fomentadores da cidadania, contudo, seu papel nessa função desfruta de um gradativo aumento de importância.

A Responsabilidade Social avança na medida em que a globalização acirra a competição entre as empresas, se afirmando como fator primordial para ganho de produtividade e respeito do público (ASHLEY, 2005).

As ações socialmente responsáveis não são frutos simplesmente de uma mudança desejada pela sociedade, mas também por um deslocamento do capitalismo visando combater as críticas (VENTURA, 2004). Elas não representam uma ameaça ao capitalismo, significam a sua solidificação e a demonstração de capacidade de criar benefícios direcionados ao bem-estar da sociedade em geral, garantindo sua aceitação ideológica e contribuindo para conter as intervenções do Estado na economia (COELHO, 2003).

\section{GESTÃO DE EMPRESAS PÚBLICAS}

Uma análise adequada do modelo de gestão de empresas públicas depende, necessariamente, do entendimento do padrão de desenvolvimento econômico e social do Brasil.

O nosso país apresenta um padrão histórico de crescimento econômico sem a perspectiva da inclusão social, comprometendo o desenvolvimento de uma cultura de cidadania. Os ciclos econômicos de crescimento, mesmo que escassos, não foram acompanhados por uma melhor distribuição de renda e pela necessária diminuição das desigualdades e ampliação do estado de bem-estar social (CARVALHO, 2003).

O Brasil apresenta um processo singular em que o estado precede a nação (FLEURY, 2004). Nossas estruturas institucionais são mais antigas do que o efetivo engajamento social e o desenvolvimento do imaginário de nacionalidade.

A participação efetiva do Estado no desenvolvimento empresarial pôde ser primeiramente verificada ao término da primeira república, com a ascensão de Getúlio Vargas ao poder na década de 1930. Foi possível observar nesse período um novo modelo de relações Estado X Sociedade. A base desse ciclo de desenvolvimento do 
Estado fundou-se no financiamento público do país, no desenvolvimento da indústria de base nacional e na interação do capital nacional e internacional.

Deste período inicial até o governo militar que se estabeleceu em 1964, foi possível observar uma estrutura industrial desenvolvida, porém, sem capacidade de sustentação financeira, competitiva e tecnológica. Foi possível sentir nas décadas de 1970 e 1980 o esgotamento do modelo desenvolvimentista. Ao mesmo tempo em que esse esgotamento se operou, verificou-se uma maior organização da sociedade civil em uma série de frentes com demandas distintas. Conforme nos afirma FLEURY (2004), a década de 1980 representou a explosão da sociedade civil em múltiplas formas de organização, reivindicando representatividade democrática de seus diversos interesses na esfera pública.

A constituição de 1988, que revelou um complexo equilíbrio de forças liberalizantes e estatizantes, surgiu neste contexto. Conhecida como a constituição cidadã, assumiu vários aspectos dessa efervescência da sociedade civil e, como fator estrutural importante, iniciou as ações de descentralização e atribuição de maior eficiência ao Estado. Nesse novo cenário, era impreterível a modernização e inserção do país na competitiva nova ordem mundial. A partir desse momento já foi possível verificar a equiparação das empresas públicas às privadas nas dimensões trabalhista, fiscal e tributária.

Nesse contexto surgiu o movimento da reforma da administração pública que teve seu auge na década de 1990, afetando, inclusive, o modelo de gestão das empresas públicas, após um amplo processo de privatizações e recolocação do Estado no ambiente empresarial (FLEURY, 2004).

No rastro do fenômeno de redução dos gastos públicos que se operou em nível mundial, o Brasil, afetado por uma crônica crise fiscal e com deficits constantes no aparelho estatal, sofreu em 1995 uma ampla reforma administrativa, que alterou de forma relevante os modelos de gestão do Estado e de suas empresas. Neste momento de nossa história é possível observar uma mudança dos paradigmas de gestão das empresas públicas. Com base nos diagnósticos de crise latente existente no modelo de administração e financiamento do Estado, operou-se uma mudança empreendida pelo então ministro Luiz Carlos Bresser Pereira por meio do Plano Diretor de Reforma do Aparelho do Estado - PDRE - baseada na constituição de uma administração gerencial focada eminentemente nos resultados empresariais das instituições.

Cria-se a partir dessas mudanças estruturais a percepção de uma profissionalização das empresas públicas, uma espécie de indução para um processo de mudança gradual e efetiva no modelo de gestão das empresas, principalmente nas dimensões institucionais, legais e culturais (RIBEIRO, 2002).

Nesse cenário globalizado, os profissionais e gestores apresentam-se expostos ao mesmo universo de competitividade e, por conseguinte, das mesmas ferramentas e modelos de gestão necessárias para tal, fazendo com que a gestão das empresas 
públicas apresente-se cada vez mais alinhada com a gestão das empresas privadas. O princípio da eficiência, já presente nos primórdios da Teoria da Administração, faz com que (independentemente do segmento de atuação - no caso público ou privado) a agilidade nas decisões, a flexibilidade nas estratégias, a rapidez no atendimento às demandas do mercado, o foco nos resultados, a formulação de planos estratégicos e a implantação e manutenção de programas de qualidade sejam fatores constantes em uma boa prática de gestão e governança corporativa.

Desde a década de 1990 as instituições atuam num contexto - sociopolítico, econômico e cultural - cada vez mais complexo que possibilita e influencia sua ação estratégica, porém, é indissociável a idéia de que as empresas, principalmente as públicas, devam atuar de modo a contribuir para o bem-estar da sociedade.

Um dos principais desafios da gerência pública se encontra na necessidade de integração das dimensões da eficiência e eficácia, maximizando os resultados esperados pela empresa, com a impreterível consideração do impacto das suas ações na sociedade (CARVALHO, 2004).

\section{INDICADORES DE RESPONSABILIDADE SOCIAL - O BALANÇO SOCIAL IBASE}

As discussões acerca dos Balanços Sociais no Brasil ganharam impulso durante a década de 1980 com alguns grupos de estudo existentes na Universidade de São Paulo. As mudanças sociais e políticas em andamento implicavam em outros meios de verificação do papel social desempenhado pelas empresas; o simples demonstrativo financeiro representado pelos balanços contábeis não era suficiente. Nos anos de 1990 essa discussão ganhou força com a militância do sociólogo Herbert de Souza, conhecido como Betinho.

Os Balanços Sociais têm como principal finalidade contabilizar de forma quantitativa e qualitativa a relação das empresas com seus públicos e ambientes externos e internos, representando uma espécie de instrumento contábil, em que seja possível visualizar de forma transparente e substancial, quais são as contrapartidas oferecidas pelas empresas ao benefício da sociedade, constituindo-se em última instância como um instrumento de cidadania. A necessidade de divulgação de Balanço Social representa um movimento que prevê um sistema administrativo mais humano (SANTOS, 2002).

Atualmente no Brasil não há consenso sobre a obrigatoriedade da publicação dos Balanços Sociais, apesar de o número de empresas que o publicam estarem em ascensão. Inicialmente a publicação de Balanços Sociais teve uma grande participação da Agência Nacional da Energia Elétrica - ANEEL - daí a grande participação das empresas elétricas no conjunto de empresas que publicam os balanços. 
O Balanço Social do Instituto Brasileiro de Análises Sociais e Econômicas IBASE - concluído no primeiro semestre de 1997, contando com o apoio de uma Instrução Normativa da Comissão de Valores Imobiliários - CVM - reflete a necessidade e a importância da publicação de um balanço num modelo único, buscando assim a possibilidade de comparação entre as empresas e o acompanhamento do desenvolvimento das organizações ao longo do tempo.

O Balanço Social age como um instrumento que busca avaliar e multiplicar o exercício da Responsabilidade Social Corporativa. O modelo do IBASE apresenta como fator relevante o fato de ser fruto da pressão social, canalizada pela ação de uma Organização Não Governamental, na busca pela transparência nas relações entre empresas e sociedade.

Apesar de seu conteúdo de informações ainda restrito, o Balanço Social IBASE separa as contribuições efetivamente compulsórias daquelas livremente empregadas pelas empresas, contando com diretrizes gerais baseadas em indicadores sociais internos, externos, ambientais, público interno (denominado como indicadores funcionais) e com informações gerais quanto ao exercício da cidadania empresarial. Esses indicadores são mensurados por meio de uma relação com indicadores de característica efetivamente contábil (como a Receita Líquida).

\section{METODOLOGIA DE PESQUISA}

O trabalho comparativo entre as empresas públicas e as privadas quanto ao perfil de seus indicadores de Responsabilidade Social foi realizado por meio de um estudo de caráter exploratório, com a realização de uma revisão bibliográfica sobre os temas e por uma pesquisa documental. Esta pesquisa documental foi realizada com base nas empresas detentoras do Selo Balanço Social IBASE no ano de 2004.

$\mathrm{O}$ instrumento principal de pesquisa foi representado pelo Modelo de Apresentação do Balanço Social IBASE (vide Figura 1), divulgado por 54 empresas em 2004, sendo delas 42 empresas privadas e 12 empresas públicas.

A definição do conjunto de empresas públicas, neste universo de pesquisa, estabeleceu-se por meio de pesquisa documental das informações institucionais sobre o modo de constituição jurídica, demonstrativos financeiros, relatórios de administração ou relatórios de participação e composição acionária, disponibilizados pelas empresas. Para este estudo, foram consideradas como empresas públicas o conjunto de empresas efetivamente estatais, sem participação da iniciativa privada em sua gestão e financiamento, e aquelas de capital aberto, mas também conhecidas como de economia mista, com o Estado (em todas as suas representações federativas) ocupando o papel de acionista majoritário, responsável pelo controle da gestão financeira e administrativa. 


\begin{tabular}{|c|c|}
\hline Empresas & Empresa \\
\hline 1. Base de Cálculo & Valor (mil R\$) \\
\hline $\begin{array}{l}\text { Receita Líquida (RL) } \\
\text { Resultado Operacional (RO) } \\
\text { Folha de Pagamento Bruta (FPB) }\end{array}$ & \\
\hline 2. Indicadores Sociais Internos & Valor (mil R\$) \% sobre RL \\
\hline $\begin{array}{l}\text { Alimentação } \\
\text { Encargos sociais compulsórios } \\
\text { Previdência privada } \\
\text { Saúde } \\
\text { Segurança e medicina no trabalho } \\
\text { Educação } \\
\text { Cultura } \\
\text { Capacitação e desenvolvimento profissional } \\
\text { Creches ou auxilio-creche } \\
\text { Participação nos lucros ou resultados } \\
\text { Outros } \\
\text { Total - Indicadores Sociais Internos }\end{array}$ & \\
\hline 3. Indicadores Sociais Externos & Valor (mil R\$) \\
\hline $\begin{array}{l}\text { Educação } \\
\text { Cultura } \\
\text { Saúde e saneamento } \\
\text { Habitação } \\
\text { Esporte } \\
\text { Lazer e diversão } \\
\text { Creches } \\
\text { Alimentação } \\
\text { Combate à fome e segurança alimentar } \\
\text { Outros } \\
\text { Total das contribuições para a Sociedade } \\
\text { Tributos (excluídos encargos sociais) } \\
\text { Total Indicadores Sociais Externos }\end{array}$ & \\
\hline 4. Indicadores Ambientais & Valor (mil R\$) \\
\hline $\begin{array}{l}\text { Investimentos relacionados com a produção/operação da empresa } \\
\text { Investimentos em programas e/ou projetos externos } \\
\text { Total dos Investimentos em Meio Ambiente }\end{array}$ & \\
\hline 5. Indicadores do Corpo Funcional & \\
\hline $\begin{array}{l}N^{\circ} \text { de empregados(as) ao final do período } \\
N^{\circ} \text { de admissões durante o período } \\
N^{\circ} \text { de empregados(as) terceirizados(as) } \\
N^{\circ} \text { de estagiários(as) } \\
N^{\circ} \text { de empregados(as) acima de } 45 \text { anos } \\
N^{\circ} \text { de mulheres que trabalham na empresa } \\
\% \text { de cargos de chefia ocupados por mulheres } \\
N^{\circ} \text { de negros(as) que trabalham na empresa } \\
\% \text { de cargos de chefia ocupados por negros(as) } \\
N^{\circ} \text { de portadores de deficiência ou necessidades especiais }\end{array}$ & \\
\hline 6. Informações relevantes quanto ao exercício da cidadania empresarial & 2004 \\
\hline $\begin{array}{l}\text { Relação entre a maior e a menor remuneração da empresa } \\
\text { Número total de acidentes de trabalho }\end{array}$ & \\
\hline
\end{tabular}

Figura 1: Modelo do Balanço Social IBASE

Fonte: IBASE (2004). 
A utilização do Modelo de Balanço proposto permite que sejam analisadas as principais variáveis que constituem a ação empresarial socialmente responsável (indicadores sociais internos, externos, ambientais, indicadores funcionais e informações gerais quanto ao exercício da cidadania empresarial) e, principalmente, permite que uma análise comparativa seja adequadamente realizada, tendo em vista a utilização de parâmetros similares num mesmo banco de dados.

As 54 empresas objeto deste estudo foram identificadas com siglas individuais de modo a garantir o sigilo de sua identificação.

Os dados constantes nos balanços das empresas foram individualmente compilados em duas planilhas distintas, uma referente a empresas privadas e a outra a empresas públicas. Com os resultados compilados foram realizadas as tabulações finais por segmento, de modo a obter-se o panorama geral do Balanço Social das empresas em dois grandes grupos: o público e o privado. A tabulação final por segmento buscou evidenciar a média simples dos resultados das empresas e a dispersão estatística de cada uma das variáveis constituintes do Balanço Social.

Durante essa etapa, uma análise individual dos dados das empresas foi realizada de modo a identificar e excluir eventuais inconsistências nas informações. Essa análise resultou na exclusão de uma empresa $(\mathrm{ADPu})$ da base de dados das empresas públicas, diminuindo o universo de pesquisa de 12 para 11 empresas. A empresa ADPu apresentou inconsistências nos seus dados na medida em que considerava o produto final de suas operações como investimento em Responsabilidade Social e, portanto, foi excluída do universo de pesquisa, implicando na alteração dos dados globais.

A última etapa da pesquisa, que possibilitou a análise comparativa e as eventuais considerações críticas, foi representada pela tabulação comparativa entre os dados finais por segmento. Essa etapa propiciou a visualização adequada das diferenças e similaridades existentes entre o perfil de atuação socialmente responsável das empresas privadas e públicas.

As limitações referentes à metodologia adotada para este estudo exploratório residem, principalmente, no pequeno universo de pesquisa adotado frente à grande amplitude e à complexidade representada pelo conceito de Responsabilidade Social e da quantidade crescente de empresas que têm desenvolvido ações socialmente responsáveis.

\section{RESULTADOS DA PESQUISA}

Ao final do processo de compilação, tabulação e comparação dos dados, tornouse possível observar o perfil das práticas de Responsabilidade Social implementadas pelas empresas, incluindo também, a possibilidade de comparação entre o segmento privado e o público. Os dados descritos na Tabela 1 elucidam a ação comparativa. 
Tabela 1: Dados Comparativos do Balanço Social IBASE - Empresas Privadas versus. Públicas.

$\%$ sobre Receita Líquida

\begin{tabular}{|c|c|c|c|}
\hline 1. Indicadores Sociais Internos & Privadas & & Públicas \\
\hline Alimentação & $0,95 \%$ & & $1,28 \%$ \\
\hline Encargos sociais & $4,19 \%$ & & $3,55 \%$ \\
\hline Previdência privada & $0,10 \%$ & & $0,92 \%$ \\
\hline Saúde & $0,54 \%$ & & $0,90 \%$ \\
\hline Segurança no trabalho & $0,20 \%$ & & $0,04 \%$ \\
\hline Educação & $0,08 \%$ & & $0,03 \%$ \\
\hline Cultura & $0,05 \%$ & & $0,02 \%$ \\
\hline Capacitação profissional & $0,15 \%$ & & $0,21 \%$ \\
\hline Creches & $0,02 \%$ & & $0,05 \%$ \\
\hline PLR & $0,60 \%$ & & $0,58 \%$ \\
\hline Outros & $0,58 \%$ & & $0,18 \%$ \\
\hline Total & $7,47 \%$ & & $7,77 \%$ \\
\hline 2. Indicadores Sociais Externos & Privadas & & Públicas \\
\hline Educação & $0,04 \%$ & & $0,07 \%$ \\
\hline Cultura & $0,08 \%$ & & $0,20 \%$ \\
\hline Saúde e saneamento & $0,01 \%$ & & $0,55 \%$ \\
\hline Habitação & $0,00 \%$ & & $0,00 \%$ \\
\hline Esporte & $0,03 \%$ & & $0,03 \%$ \\
\hline Lazer e diversão & $0,00 \%$ & & $0,00 \%$ \\
\hline Creches & $0,00 \%$ & & $0,00 \%$ \\
\hline Alimentação & $0,00 \%$ & & $0,00 \%$ \\
\hline Combate à fome & $0,52 \%$ & & $0,00 \%$ \\
\hline Outros & $0,12 \%$ & & $0,94 \%$ \\
\hline Subtotal & $0,76 \%$ & & $1,78 \%$ \\
\hline Tributos & $14,16 \%$ & & $23,40 \%$ \\
\hline Total & $14,92 \%$ & & $25,19 \%$ \\
\hline \multicolumn{2}{|l|}{ 3. Indicadores Ambientais } & Privadas & Públicas \\
\hline \multicolumn{2}{|c|}{$\begin{array}{l}\text { Investimentos relacionados com a produção/operação } \\
\text { da empresa }\end{array}$} & $0,56 \%$ & $3,09 \%$ \\
\hline \multicolumn{2}{|c|}{ Investimentos em programas e/ou projetos externos } & $0,05 \%$ & $0,07 \%$ \\
\hline \multicolumn{2}{|c|}{ Total dos Investimentos em Meio Ambiente } & $0,61 \%$ & $3,17 \%$ \\
\hline \multicolumn{4}{|l|}{ 4. Indicadores do Corpo Funcional } \\
\hline \multicolumn{2}{|c|}{$\%$ de cargos de chefia ocupados por mulheres } & $13,00 \%$ & $24,00 \%$ \\
\hline \multicolumn{2}{|c|}{$\%$ de cargos de chefia ocupados por negros(as) } & $6,00 \%$ & $7,00 \%$ \\
\hline \multicolumn{2}{|c|}{ \% de portadores de deficiência ou necessidades especiais } & $1,84 \%$ & $2,24 \%$ \\
\hline
\end{tabular}

Fonte: Elaborada pelo Autor. 
Indicadores de responsabilidade social: estudo comparativo entre empresas públicas e privadas, baseado no balanço...

Dentre os resultados comparativos obtidos, destacam-se:

- Os dados totalizados dos Indicadores Sociais Internos, incluindo variáveis de caráter compulsório legal como Encargos Fiscais, não apresentam diferenças relevantes entre as empresas privadas e públicas;

- O Indicador Social Interno referente aos investimentos em previdência privada é significativamente superior nas empresas públicas;

- Os dados totalizados dos Indicadores Sociais Externos, considerados como as variáveis mais visíveis e tradicionais das ações de Responsabilidade Social, apresentam as empresas públicas ocupando um papel preponderante, com nível de investimento $70 \%$ superior ao investido pelas empresas privadas. $\mathrm{O}$ investimento superior por parte das empresas públicas recebe contribuição significativa do Indicador Social Externo referente aos tributos;

- Os Indicadores Ambientais apresentam as empresas públicas ocupando um papel preponderante, com nível de investimento em ações e programas ambientais cinco vezes superior ao investido pelas empresas privadas;

- As empresas públicas apresentam papel preponderante na inclusão de mulheres e negros em cargos de chefia e na inclusão de portadores de necessidades especiais no seu corpo funcional;

- O tratamento estatístico dos dados demonstra que, tanto nas empresas privadas quanto nas públicas, existe uma grande dispersão entre o montante investido pelas diferentes empresas nas diversas variáveis que compõem o Balanço Social IBASE. Essa grande dispersão se mostra presente nas empresas do mesmo segmento (privadas e públicas); e

- Independentemente dos valores percentuais relativos à receita líquida utilizados pelas empresas na apresentação dos seus Balanços Sociais, a diferença real (em termos monetários) dos montantes investidos apresenta um elevado desequilíbrio entre as empresas privadas e as públicas. A receita líquida (RL) média referente às empresas privadas perfaz aproximadamente 1,1 Bilhões de Reais, enquanto a RL média das empresas públicas perfaz um montante aproximado de 15,0 Bilhões de Reais.

\section{CONSIDERAÇÕS CRÍTICAS E CONCLUSÕES}

Um estudo exploratório, como o desenvolvido por este trabalho, sempre apresenta algumas restrições e limitações de aspecto teórico que devem ser consideradas nesta etapa. Este estudo buscou aumentar o conhecimento sobre o fenômeno da Responsabilidade Social, através de uma abordagem específica, trazendo o Estado e suas empresas para a perspectiva de análise. A definição das relações causais que 
expliquem os resultados encontrados depende, necessariamente, de outros estudos. As considerações propostas no momento devem ser entendidas neste sentido.

\section{Considerações alinhadas aos objetivos centrais}

Quanto à verificação das diferenças e similaridades das ações de Responsabilidade Social desenvolvidas pelas empresas públicas e privadas, pode-se observar que, no aspecto global, as empresas públicas assumem papel preponderante nas ações socialmente responsáveis. Em 14 dos 26 indicadores abordados pelo Balanço Social IBASE, visualiza-se maior aporte de investimento por parte das empresas públicas, restando apenas quatro indicadores demonstrando vantagem às empresas privadas e em oito deles não são verificadas diferenças significativas. Em termos dos Indicadores Globais (totalizados), representados pelos Indicadores Sociais Internos e Externos, Ambientais e referentes ao Corpo Funcional, as empresas públicas apresentam-se na liderança dos investimentos em sua totalidade. Mesmo que não seja possível estabelecer de forma assertiva relações efetivamente causais, dadas as limitações da pesquisa e do universo de empresas ainda a ser explorado, podese verificar que empresas públicas parecem preencher, de forma mais significativa que as privadas, lacunas não atendidas pelos agentes públicos governamentais (na garantia do bem-estar à sociedade). As empresas públicas agindo como agentes de reparação da ineficiência e ineficácia histórica do Estado Brasileiro na sua limitada capacidade administrativa de planejamento e alocação de recursos.

Outra consideração relevante diz respeito aos Indicadores Internos abordados de forma global. Eles revelam um nivelamento entre os montantes investidos pela empresas públicas e as privadas. $\mathrm{O}$ aspecto compulsório legal representado por muitos desses indicadores pode contribuir para esse fato, suscitando as discussões sobre a importância e a necessidade de uma legislação específica para a regulamentação de determinadas ações de Responsabilidade Social, conforme projeto já apresentado no Congresso Nacional pela então deputada Marta Suplicy.

Um outro fator que chama atenção e que, necessariamente, deve ser objeto de estudos mais aprofundados, é representado pela acentuada diferença representada pelo Indicador Social Externo relativo aos Tributos, em que as empresas públicas apresentam um volume de contribuições de 23,40\% da Receita Líquida contra 14,16\% das empresas privadas. Hipóteses de explicação para tal divergência podem residir em fatores como (1) a efetiva diferença entre a tributação dos segmentos de atuação dos dois grupos de empresa, (2) os artifícios legais utilizados pelas empresas privadas na escolha de uma tributação menos onerosa ou (3) incentivos fiscais e tributários oferecidos pelo Estado (em todas as suas esferas de representação federativa) para desenvolvimento da iniciativa privada. 
Quanto à visualização das características de investimento em ações socialmente responsáveis especificamente nas empresas públicas, pode-se observar que existe foco no investimento nas ações de preservação ambiental e na capacidade de inclusão de minorias ou setores desfavorecidos da sociedade no seu quadro funcional, corroborando com a idéia de predileção por ações de tradicional responsabilidade do Estado.

Ainda no aspecto do papel específico das empresas públicas, pode-se observar que o volume dos recursos investidos em termos reais monetários, produto de suas grandes estruturas organizacionais e segmentos estratégicos de atuação (como Petróleo e Energia Elétrica), é extremamente elevado, principalmente quando comparado a outros segmentos empresariais. Tal afirmação é extremamente relevante quando se analisa o real impacto desses investimentos nos projetos socialmente responsáveis patrocinados.

\section{Considerações outras reveladas pela pesquisa realizada}

O papel preponderante ocupado pelo Indicador de Responsabilidade Externo representado pelos Tributos pode falsear o entendimento quanto ao efetivo aproveitamento dos recursos por parte da sociedade, pois dependem diretamente da ação do Estado na sua alocação, contingenciamento e distribuição. Uma forma eficaz de verificação clara dos públicos beneficiados pelas ações de Responsabilidade Social pressupõe uma análise mais detalhada da aplicabilidade ou inaplicabilidade desse indicador.

Outra limitação inerente ao estudo da Responsabilidade Social Empresarial é representada pela alta dispersão dos valores de um mesmo indicador nas empresas dos segmentos estudados, sugerindo que os investimentos em ações de Responsabilidade Social não são uma constante e não se distribuem de forma estável nas empresas estudadas. $\mathrm{O}$ investimento nessas ações ainda depende de ações individuais das instituições, não representando uma prática disseminada e regulada pelo senso comum.

Por fim, recomenda-se realizar estudos de maior profundidade para novas interpretações ou detalhamentos das considerações aqui propostas. A Responsabilidade Social representa um tema amplo, complexo e que se desenvolve rapidamente no meio empresarial e na própria sociedade. Corroborado pelo fato de sua inserção acadêmica ainda apresentar-se em fase inicial, o assunto representa uma grande possibilidade para o desenvolvimento de novos trabalhos. 


\title{
SOCIAL RESPONSIBILITY SCORE: COMPARATIVE STUDY BETWEEN PUBLIC AND PRIVATE COMPANIES, BASED IN IBASE SOCIAL STAMP
}

\begin{abstract}
The present article intends to arguing the existing differences and similarities between Social Responsibility actions and praticals developed by the private and public companies. This comparative study of exploring character was carried with the companies owners of Social Stamp IBASE, wich published its Social Balances in the model considered for the institute in the year of 2004. For such, beyond the documentary research involving the published balances, a conceptual revision over the main subjects was necessary and also it constitutes part of the study. The joined results supply measurable and representative information about the main characteristics of social action of the companies, propitiating a comparative analysis and the emission of critical considerations, that do not finish themselves, but establishes a possibility of different readings concerning the models of social responsible management undertaken by companies from public and private segments.
\end{abstract}

Keywords: Social Responsibility. Social Balance. Social Responsibility Score. Public Companies.

\section{REFERÊNCIAS}

ASHLEY, Patrícia Almeida (Org.). Ética e Responsabilidade Social nos Negócios. São Paulo: Saraiva, 2005.

BORGER, Fernanda. Responsabilidade Social: efeitos da Atuação Social na dinâmica empresarial. São Paulo, 2001. Tese de Doutorado. Faculdade de Economia, Administração e Contabilidade - Universidade de São Paulo. 2001.

CARVALHO, José Murilo de. Cidadania no Brasil: o longo caminho. Rio de Janeiro: Civilização Brasileira, 2003.

CARVALHO, Maria do Socorro M. V. Desafios Contemporâneos da Gestão. Revista de Administração Pública, FGV, Rio de Janeiro, mar/abr 2004, vol. 38 (02), p.307-16.

CHAN, Betty Lílian. Destinação de riquezas aos acionistas e aos empregados: comparação entre empresas estatais e privadas do setor de serviços públicos. In: ENANPAD, 2004, Curitiba, Anais XVIII ENANPAD, Rio de Janeiro, ANPAD, 2004. 
Indicadores de responsabilidade social: estudo comparativo entre empresas públicas e privadas, baseado no balanço...

COELHO, Michele Q. Indicadores de Perfomance para Projetos Sociais: A Perspectiva dos Stakeholders. In: Congresso Latino Americano de Ética, Negócios e Economia, 2003, São Paulo. ALENE, 2003.

FLEURY, Sonia. Brasil: uma agenda de reformas. Revista de Administração Pública, FGV, Rio de Janeiro, nov/dez 2004, vol. 38 (06), p.1085-94.

IBASE - Instituto Brasileiro de Análises Sociais e Econômicas. Título do texto utilizado??. Disponível em: $<$ http://www.ibase.org.br>. Acesso em: 30 set. 2005.

KREITLON, Maria Priscilla. A Ética nas Relações entre Empresas e Sociedade: Fundamentos Teóricos da Responsabilidade Social Empresarial. In: ENANPAD, 2004, Curitiba, Anais XVIII ENANPAD, Rio de Janeiro, ANPAD, 2004.

NETO, Francisco P. M.; FROES, César. Gestão da Responsabilidade Social Corporativa: o caso brasileiro. Rio de Janeiro: Qualitymark, 2004.

RIBEIRO, Sheila Maria Reis. Reforma do Aparelho de Estado no Brasil: uma comparação entre os anos 60 e 90. In: VII Congresso Internacional del CLAD sobre la Reforma del Estado y de la Administración Pública, Lisboa, Portugal, 2002.

SANTOS, Luiz Carlos dos. Balanço Social: demonstração da cidadania organizacional - Revista ADM Pública: Vista \& Revista, Universidade do Estado da Bahia, Salvador, set/dez 2002, n. 2, p. 39-42.

VENTURA, Elvira Cruvinel Ferreira. Responsabilidade Social das Empresas sob a Ótica do "Novo Espírito do Capitalismo". In: ENANPAD, 2004, Curitiba, Anais XVIII ENANPAD, Rio de Janeiro, ANPAD, 2004. 